\title{
Erratum
}

\section{EXACT ANALYSIS OF SPURIOUS SIGNALS IN DIRECT DIGITAL FREQUENCY SYNTHESIZERS DUE TO AMPLITUDE QUANTIZATION ${ }^{1}$}

\author{
Tian Xinguang Zhang Eryang* \\ (Institute of Computing Technology, Beijing Jiaotong University, Beijing 100029, China) \\ * School of Electronic Science and Engineering, National University of Defense Technology, \\ Changsha 410073, China)
}

DOI $10.1007 / \mathrm{s} 11767-009-1002-6$

The original online version of this article (Journal of Electronics (China), Vol. 26, No.4, July 2009, pp.448-455; DOI: 10.1007/s11767-008-0155-z) unfortunately contains two mistakes on the left column of Page 450. An extra right bracket in Eq.(3), the correct form of Eq.(3) is given below:

$$
\begin{aligned}
r(n)= & \frac{1}{2^{L-1} a} \operatorname{round}\left\{2 ^ { L - 1 } a \operatorname { s i n } \left[2 \pi 2 ^ { B } \operatorname { t r u n c } \left(n K / 2^{B}\right.\right.\right. \\
& \left.\left.\left.+P / 2^{B}\right) / 2^{N}\right]\right\}-\sin \left[2 \pi 2 ^ { B } \operatorname { t r u n c } \left(n K / 2^{B}\right.\right. \\
& \left.\left.+P / 2^{B}\right) / 2^{N}\right]
\end{aligned}
$$

and one "/" missing in $\left[-2^{-L} a, 2^{-L} / a\right]$ of line 4 from the bottom, the correct form should be $\left[-2^{-L} / a, 2^{-L} / a\right]$. 